\section{(6) OPEN ACCESS}

\title{
Identification of novel microbes associated with pelvic inflammatory disease and infertility
}

\author{
Catherine L Haggerty, ${ }^{1,2}$ Patricia A Totten, ${ }^{3}$ Gong Tang, ${ }^{1}$ Sabina G Astete, ${ }^{2}$ \\ Michael J Ferris, ${ }^{4}$ Johana Norori, ${ }^{4}$ Debra C Bass, ${ }^{1}$ David H Martin, ${ }^{5}$ Brandie D Taylor, ${ }^{1}$ \\ Roberta B Ness ${ }^{6}$
}

- Additional material is published online only. To view please visit the journal online (http://dx.doi.org/10.1136/ sextrans-2015-052285).

${ }^{1}$ University of Pittsburgh, Graduate School of Public Health, Pittsburgh, Pennsylvania, USA

${ }^{2}$ Magee-Womens Research Institute, Pittsburgh, Pennsylvania, USA ${ }^{3}$ Department of Medicine, Division of Infectious Diseases, University of Washington, Seattle, Washington, USA

${ }^{4}$ Departments of Pediatrics and Microbiology, Louisiana State University, New Orleans, Louisiana, USA

${ }^{5}$ Department of Medicine, Louisiana State University, New Orleans, Louisiana, USA ${ }^{6}$ The University of Texas School of Public Health, Houston, Texas, USA

\section{Correspondence to} Dr Catherine L Haggerty, Department of Epidemiology, University of Pittsburgh, 130 DeSoto Street, 516B Parran Hall, Pittsburgh, PA 15261, USA; haggerty@pitt.edu

Received 6 August 2015 Revised 5 December 2015 Accepted 30 December 2015 Published Online First 29 January 2016

\section{CrossMark}

\footnotetext{
To cite: Haggerty $\mathrm{CL}$, Totten PA, Tang G, et al. Sex Transm Infect 2016;92:441-446.
}

\section{ABSTRACT \\ Objectives As pelvic inflammatory disease (PID)} aetiology is not completely understood, we examined the relationship between select novel bacteria, PID and longterm sequelae.

Methods Fastidious bacterial vaginosis (BV)-associated bacteria (Sneathia (Leptotrichia) sanguinegens, Sneathia amnionii, Atopobium vaginae and BV-associated bacteria 1 (BVAB1)), as well as Ureaplasma urealyticum and Ureaplasma parvum were identified in cervical and endometrial specimens using organism-specific PCR assays among 545 women enrolled in the PID Evaluation and Clinical Health study. Risk ratios and 95\% Cls were constructed to determine associations between bacteria, histologically confirmed endometritis, recurrent PID and infertility, adjusting for age, race, gonorrhoea and chlamydia. Infertility models were additionally adjusted for baseline infertility.

Results Persistent detection of BV-associated bacteria was common (range $58 \%$ for $A$. vaginae to $82 \%$ for BVAB 1) and elevated the risk for persistent endometritis $\left(\mathrm{RR}_{\mathrm{adj}} 8.5,95 \% \mathrm{Cl} 1.6\right.$ to 44.6$) 30$ days post-cefoxitin/doxycycline treatment, independent of gonorrhoea and chlamydia. In models adjusted for gonorrhoea and chlamydia, endometrial BV-associated bacteria were associated with recurrent PID $\left(R_{\mathrm{adj}} 4.7\right.$, $95 \% \mathrm{Cl} 1.7$ to 12.8$)$, and women who tested positive in the cervix and/or endometrium were more likely to develop infertility ( $\operatorname{RR}_{\text {adj }} 3.4,95 \% \mathrm{Cl} 1.1$ to 10.4$)$. Associations between ureaplasmas and PID sequelae were modest.

Conclusions To our knowledge, this is the first prospective study to demonstrate that $S$. sanguinegens, S. amnionii, BVAB1 and $A$. vaginae are associated with PID, failure of the Centers for Disease Control and Prevention-recommended treatment to eliminate shortterm endometritis, recurrent PID and infertility. Optimal antibiotic regimens for PID may require coverage of novel BV-associated microbes.

\section{INTRODUCTION}

Pelvic inflammatory disease (PID), infection and inflammation of the uterine lining (endometritis) and fallopian tubes (salpingitis), is a frequent condition among young women that often results in tubal factor infertility, chronic pelvic pain and recurrent PID. ${ }^{1}$ Tubal factors account for approximately a quarter of infertility with a significant proportion linked to prior PID. ${ }^{2}$ A primary treatment option is in vitro fertilisation, which is costly and results in lower birth rates than among women with other forms of infertility, particularly if hydrosalpinx is present. $^{3}$

Although PID is a recognised complication of Chlamydia trachomatis and Neisseria gonorrhoeae infections, ${ }^{45}$ the aetiology of up to $70 \%$ of cases is unknown. One clue about the trigger for nongonococcal/non-chlamydial cases is the association between PID and bacterial vaginosis (BV), a condition marked by vaginal overgrowth of anaerobic bacterial species. ${ }^{6}$ Anaerobic Gram-negative rods, frequently present in BV flora, have been cultured from the upper genital tract in women with PID. ${ }^{7}$ Recent application of culture-independent broadrange PCR and bacterial 16S rRNA gene sequencing has identified specific, novel bacterial species in $\mathrm{BV}^{8} \quad$ Gram-negative anaerobes Sneathia (Leptotrichia) sanguinegens/amnionii have been linked in case reports to postpartum fever, ${ }^{9}$ endometritis, ${ }^{9}$ tuboovarian abscesses, ${ }^{10}$ amnionitis and preterm labour. ${ }^{11}$ The Gram-positive anaerobe Atopobium vaginae has been associated with tuboovarian abscess, tubal factor infertility, ${ }^{12}$ endometritis $^{13}$ and fetal death. ${ }^{14}$ Totten et al identified bacterial $16 \mathrm{~S}$ sequences in the fallopian tubes of $24 \%$ of women with salpingitis but in none of controls, ${ }^{15}$ including phylotypes closely related to Sneathia and A. vaginae.

Emerging evidence implicates Mycoplasma genitalium as a significant aetiological agent of PID, ${ }^{16}{ }^{17}$ yet less is known about the role of other mollicutes, including ureaplasmas, in PID. Undifferentiated Ureaplasma spp. have been crosssectionally associated with PID and infertility, ${ }^{18}$ although not consistently. ${ }^{6}$ Recently, the two biovars of Ureaplasma urealyticum have been classified as separate species: ${ }^{19}$ U. urealyticum, which has been associated with urethritis in men and Ureaplasma parvum that has not. ${ }^{20}$

As there have been no prospective studies examining the role of recently identified fastidious BV-associated bacteria or the newly differentiated ureaplasma species in PID or its sequelae, we examined the relationships among the BV-associated bacteria $S$. sanguinegens, S. amnionii, A. vaginae, BVAB1, as well as U. urealyticum and U. parvum, and the outcomes of histologically confirmed endometritis, post-treatment endometritis, recurrent PID, infertility and chronic pelvic pain in a cohort of women with PID followed for a mean of 7 years. 


\section{MATERIALS AND METHODS \\ Patient population}

Women who participated in the PID Evaluation and Clinical Health (PEACH) study and had archived cervical and endometrial specimens were studied. The PEACH study methods have been described in detail elsewhere. ${ }^{4}$ Briefly, 831 women aged 14-37 years with clinically suspected PID (pelvic pain $<30$ days duration, pelvic organ tenderness and leucorrhoea, mucopurulent cervicitis or untreated cervicitis) were recruited between March 1996 and February 1999 from emergency departments, OB/GYN clinics, STD clinics and private practices at 13 US clinical sites and randomised to inpatient or outpatient cefoxitin and doxycycline treatment.

\section{Endometrial biopsies and microbiological studies}

At baseline and 30 days, an endometrial biopsy was obtained for histology, chlamydial PCR (Roche Diagnostics), M. genitalium $\mathrm{PCR}^{16}$ and gonococcal culture. A modification ${ }^{21}$ of the criteria proposed by Kiviat et $a l^{5}$ was used to diagnose endometritis, defined by at least five neutrophils in the endometrial surface epithelium in the absence of menstrual endometrium and/or at least two plasma cells in the endometrial stroma. Cervical swabs were used for $N$. gonorrhoeae culture and C. trachomatis and M. genitalium ${ }^{16}$ PCR.

For this substudy, previously frozen endometrial biopsy $(\mathrm{N}=609)$ and cervical swab $(\mathrm{N}=691)$ specimens stored in $-80^{\circ} \mathrm{C}$ freezers were thawed, purified using the MasterPure DNA purification kit for patient specimens (Epicentre) and tested by speciesspecific PCR assays. The preservation of bacterial DNA suitable for PCR analysis of specimens stored long term under these conditions has been previously demonstrated. ${ }^{22}$ Specimens and endometrial histology were available from 545 women, with occasional missing assessments of specific bacterium. PCR assays for $S$. sanguinegens/amnionii, A. vaginae, and BVAB1 were performed as previously described, ${ }^{23}$ and the U. urealyticum and U. parvum assays were performed using a modification of the procedure of Xiao et al. ${ }^{25}$ Separate tests were performed for each specie and contained $1 \times$ PCR buffer $\left(\mathrm{Mg}^{++}\right.$free, Promega), $5 \mathrm{mM} \mathrm{MgCl}_{2}$, $5 \mathrm{U}$ Taq DNA polymerase; $200 \mu \mathrm{M}$ of each of the four dNTPs and the primers described by Xiao et $a l^{25}(0.2$ and $0.3 \mu \mathrm{M}$ for the forward primers of $U$. urealyticum and $U$. parvum, respectively, and $0.5 \mu \mathrm{M}$ for both reverse primers) and $2 \mu \mathrm{L}$ of purified patient specimen in a total volume of $100 \mu \mathrm{L}$. PCR was performed in the Viia7 real-time PCR system (Applied Biosystems) under amplification conditions of: initial denaturation $\left(95^{\circ} \mathrm{C}\right.$ for $10 \mathrm{~min}$ ) and the following cycling programme (40 cycles): denaturation: $95^{\circ} \mathrm{C}$ for $15 \mathrm{~s}$, annealing at $55^{\circ} \mathrm{C}$ for $50 \mathrm{~s}$ and extension at $72^{\circ} \mathrm{C}$ for $45 \mathrm{~s}$, final elongation at $72^{\circ} \mathrm{C}$ for $10 \mathrm{~min}$, and a final soak set at $4^{\circ} \mathrm{C}$ indefinitely. U. urealyticum and $U$. parvum PCR assay specificities were confirmed by detection of the appropriate sized PCR product (152 bp for U. urealyticum and U. parvum) on agarose gels and reactivity with the $U$. urealyticum biotin labelled UU127\#1 probe $\left(5^{\prime} \text {-biotin-ACACGAGTATGGATGAAATCAAAATCATCAAA-3' }\right)^{25}$ and U. parvum UP063\#1 probe (5'-biotin-CCCATTTCAGCCAT GGTGCCATCA- $\left.3^{\prime}\right)^{25}$ on Southern blots hybridised at $58^{\circ} \mathrm{C}$ and $60^{\circ} \mathrm{C}$, respectively, then visualised on Kodak BioMax XAR film after reaction in the chemiluminescence assay using the ECL kit (Amercham). Inhibition testing was performed using the M. genitalium internal control assay ${ }^{26}$ on every 10th specimen negative for all assays; no inhibition was detected.

\section{Follow-up}

Participants were monitored with in-person visits at 5 and 30 days and telephone interviews every 3-4 months until June
2004, at which point we had follow-up information for 541 women, representing a mean follow-up of 84 months. Infertility was defined when a sexually active woman with at least 12 months of follow-up did not report conception (positive urine or blood test or doctor's diagnosis) despite rare or no use of a contraceptive method. Chronic pelvic pain was defined as pain reported during at least two consecutive interviews, suggesting a minimum of 6 months duration. Recurrent PID was self-reported and confirmed in $76 \%$ of medical records. ${ }^{4}$ Since few women experienced an ectopic pregnancy $(\mathrm{N}=6)$, we did not include as an outcome.

\section{Statistical methods}

In our primary analysis, cross-sectional associations between bacteria and endometritis were determined using logistic regression models, adjusted for age and race. Logistic regression was used to construct relative risks and 95\% CIs between each bacterium and endometritis at 30 days, recurrent PID, infertility and chronic pelvic pain, and included age, and race as explanatory variables. Models predicting infertility and post-treatment endometritis were adjusted for age, race, gonorrhoea, chlamydia, self-reported infertility at baseline and self-reported partner treatment, respectively. In exploratory analyses, all the above models were additionally analysed in a subset of women negative for both chlamydia and gonorrhoea (see web appendix). Subsequent exploratory models included terms representing interactions between BV-associated bacteria and chlamydia/ gonorrhoea. Analyses were conducted first using both cervical and endometrial PCR results combined and were then repeated using only endometrial PCR. SPSS V.20.0 for Windows was used for statistical comparisons.

\section{RESULTS}

S. sanguinegens (54\%), S. amnionii (66\%), A. vaginae (83\%), BVAB1 (65\%), U. urealyticum (30\%) and U. parvum (58\%) were commonly isolated from the cervix and/or endometrium. As expected, S. sanguinegens, S. amnionii, A. vaginae and BVAB1 were significantly associated with BV determined by Nugent's ${ }^{27}$ and Amsel's ${ }^{28}$ criteria $(\mathrm{p}<0.0001$ for all comparisons). Cervical identification was strongly associated with endometrial identification, suggesting lower to upper genital tract ascension (S. sanguinegens: OR 9.6, 5.8-15.9; S. amnionii: OR 12.1, 7.8-19.0; A. vaginae: OR 4.3, 2.8-6.7; BVAB1: OR 2.8, 2.0-4.1; U. urealyticum: OR 20.3,9.5-43.0; U. parvum: OR $13.1,6.7-25.8)$. Women testing positive for each of these bacteria in the cervix were significantly more likely to test positive for each of the other bacteria $(p<0.05$ for all comparisons) with the exception of $U$. parvum, which was not associated with any other bacteria. Similarly, endometrial identification of each bacteria was linked to endometrial detection of the other bacteria $(\mathrm{p}<0.05$ for all comparisons). The exception was BVAB1, which was not associated with ureaplasmal bacteria. S. sanguinegens and $S$. amnionii, two closely related Gram-negative anaerobes, co-occurred in the endometrium in $97 \%$ of samples testing positive for S. sanguinegens and in 52\% of samples testing positive for $S$. amnionii. As $S$. sanguinegens, S. amnionii, $A$. vaginae and BVAB1 thus constituted a microbial community (as previously reported among women with BV), ${ }^{29}$ we termed them 'fastidious BV-associated bacteria' and grouped them together in remaining analyses.

Women testing positive versus negative for any or all four fastidious BV-associated bacteria in the endometrium at baseline were at significantly elevated risk for endometritis (table 1). Cervical and/or endometrial fastidious BV-associated bacteria 
Table 1 Associations between selected fastidious bacterial vaginosis-associated bacteria (BVAB) ${ }^{*}$, ureaplasmal bacteria and histologically confirmed endometritist

\begin{tabular}{|c|c|c|c|}
\hline & $\begin{array}{l}\text { Endometritis+ } \\
\mathrm{n}=258 \\
\mathrm{n} / \mathrm{N}(\%)\end{array}$ & $\begin{array}{l}\text { Endometritis- } \\
\mathrm{n}=287 \\
\mathrm{n} / \mathrm{N}(\%)\end{array}$ & $\begin{array}{l}\text { Adjusted OR‡ } \\
(95 \% \mathrm{CI})\end{array}$ \\
\hline \multicolumn{4}{|c|}{ BVAB $^{*}(1$ or more +$)$} \\
\hline $\begin{array}{l}\text { Cervix and/or } \\
\text { endometrium }\end{array}$ & $233 / 258(90.3)$ & 250/287 (87.1) & $1.1(0.6$ to 2.0$)$ \\
\hline Endometrium & $183 / 247(74.1)$ & $166 / 270(61.5)$ & 1.6 (1.1 to 2.4$)$ \\
\hline \multicolumn{4}{|l|}{$\mathrm{BVAB}^{*}$ (all +) } \\
\hline $\begin{array}{l}\text { Cervix and/or } \\
\text { endometrium }\end{array}$ & 93/118 (78.8) & $81 / 118(68.6)$ & 1.3 (0.7 to 2.6$)$ \\
\hline Endometrium & $27 / 93(29.0)$ & 18/129 (14.0) & 2.0 (1.0 to 4.0$)$ \\
\hline \multicolumn{4}{|c|}{ Ureaplasma urealyticum } \\
\hline $\begin{array}{l}\text { Cervix and/or } \\
\text { endometrium }\end{array}$ & 75/247 (30.4) & 70/271 (25.8) & 1.2 (0.8 to 1.8$)$ \\
\hline Endometrium & 24/254 (9.4) & $22 / 281(7.8)$ & 1.2 (0.6 to 2.2 ) \\
\hline \multicolumn{4}{|c|}{ Ureaplasma parvum } \\
\hline $\begin{array}{l}\text { Cervix and/or } \\
\text { endometrium }\end{array}$ & $128 / 252(50.8)$ & $164 / 276(59.4)$ & 0.7 (0.5 to 1.0$)$ \\
\hline Endometrium & 47/254 (18.5) & 49/281 (17.4) & $1.1(0.7$ to 1.7$)$ \\
\hline \multicolumn{4}{|c|}{$\begin{array}{l}\text { *Sneathia sanguinegens, Sneathia amnionii, Atopobium vaginae and BVAB1. } \\
\text { Comparison group consists of women who tested negative for all four bacteria. In } \\
\text { model of 'all positive', women testing positive for some but not all bacteria are } \\
\text { excluded. } \\
\dagger \geq 5 \text { surface epithelium neutrophils per } \times 400 \text { field absent of menstrual endometrium } \\
\text { and/or } \geq 2 \text { stromal plasma cells per } \times 120 \text { field. } \\
\ddagger \text { Adjusted for age and race. }\end{array}$} \\
\hline
\end{tabular}

and chlamydia and/or gonorrhoea were highly correlated $(\mathrm{p}<0.001)$, with $36 \%$ of women testing positive for both. In a subset of women testing negative for chlamydia and gonorrhoea, results were attenuated and no models were statistically significant (see online supplementary table S1). However, the OR for endometritis associated with at least two fastidious BV-associated bacteria was significantly higher in women testing positive for chlamydia and/or gonorrhoea than that in women testing negative $\left(\mathrm{OR}_{\mathrm{adj}} 3.6,95 \% \mathrm{CI} 1.4\right.$ to 9.2$)$. The relationship between a positive test for all four BV-associated bacteria and endometritis was significant after adjustment for M. genitalium $\left(\mathrm{OR}_{\mathrm{adj}}\right.$ 5.1, 95\% CI 1.2 to 21.7). U. urealyticum and $U$. parvum were not significantly associated with endometritis.

Persistent bacterial detection after cefoxitin and doxycycline treatment was common, with $46 \%$ of women with $S$. sanguinegens, 55\% with $S$. amnionii, 82\% with BVAB1, 58\% with $A$. vaginae, $46 \%$ with $U$. urealyticum and $49 \%$ with $U$. parvumpositive baseline tests remaining positive at the 30 -day visit. In comparison, continuance of $N$. gonorrhoeae and C. trachomatis occurred among only $8 \%$ and $10 \%$ of the cohort. Endometritis persistence 30 days post-treatment befell $43 \%$ of women despite receipt of the Centers for Disease Control and Prevention (CDC)-recommended cefoxitin and doxycycline. ${ }^{4}$ Persistent endometritis was strongly linked to endometrial re-detection of the combined fastidious BV-associated bacteria (table $2, \mathrm{RR}_{\text {adj }}$ 5.7, 95\% CI 1.4 to 23.3). This relationship remained significant after excluding women with gonorrhoea and chlamydia (see online supplementary table $\mathrm{S} 2, \mathrm{RR}_{\text {adj }} 8.5,95 \%$ CI 1.6 to 44.6 ). Women who tested positive for both fastidious BV-associated bacteria and chlamydia and/or gonorrhoea did not have a further elevated risk of persistent endometritis. Endometrial $U$. urealyticum and U. paruum were associated, albeit marginally, with persistent endometritis.
Table 2 Associations between selected fastidious bacterial vaginosis-associated bacteria (BVAB) ${ }^{*}$, ureaplasmal bacteria and histologically confirmed endometritist 30 days following treatment for pelvic inflammatory disease

\begin{tabular}{|c|c|c|c|}
\hline & $\begin{array}{l}\text { Endometritis }++ \\
\mathrm{n}=175 \\
\mathrm{n} / \mathrm{N}(\%)\end{array}$ & $\begin{array}{l}\text { Endometritist- } \\
\mathrm{n}=238 \\
\mathrm{n} / \mathrm{N}(\%)\end{array}$ & $\begin{array}{l}\text { Adjusted RR } \\
(95 \% \text { Cl) }\end{array}$ \\
\hline \multicolumn{4}{|c|}{ BVAB $(1 \text { or more }+)^{*}$} \\
\hline $\begin{array}{l}\text { Cervix and/or } \\
\text { endometrium }\end{array}$ & $149 / 175(85.1)$ & 199/238 (83.6) & 1.1 (0.6 to 2.2$)$ \\
\hline Endometrium & $111 / 169(65.7)$ & $140 / 234(59.8)$ & $1.2(0.7$ to 2.0$)$ \\
\hline \multicolumn{4}{|c|}{ BVAB (all positive)* } \\
\hline $\begin{array}{l}\text { Cervix and/or } \\
\text { endometrium }\end{array}$ & $37 / 63(58.7)$ & $32 / 71(45.1)$ & 2.3 (0.9 to 5.9$)$ \\
\hline Endometrium & $11 / 69(15.9)$ & $5 / 99(5.1)$ & 5.7 (1.4 to 23.3$)$ \\
\hline \multicolumn{4}{|c|}{ Ureaplasma urealyticum } \\
\hline $\begin{array}{l}\text { Cervix and/or } \\
\text { endometrium }\end{array}$ & 40/167 (24.0) & $49 / 231(21.2)$ & 1.0 (0.5 to 1.7$)$ \\
\hline Endometrium & $15 / 170(8.8)$ & $11 / 235(4.7)$ & 1.7 (0.6 to 4.3$)$ \\
\hline \multicolumn{4}{|c|}{ Ureaplasma parvum } \\
\hline $\begin{array}{l}\text { Cervix and/or } \\
\text { endometrium }\end{array}$ & 69/169 (40.8) & $70 / 234(29.9)$ & 1.9 (1.2 to 3.2$)$ \\
\hline Endometrium & $27 / 170(15.9)$ & $31 / 235(13.2)$ & $2.0(1.0$ to 3.9$)$ \\
\hline \multicolumn{4}{|c|}{$\begin{array}{l}\text { *Sneathia sanguinegens, Sneathia amnionii, Atopobium vaginae and BVAB1. } \\
\text { Comparison group consists of women who tested negative for all four bacteria. In } \\
\text { model of 'all positive', women testing positive for some but not all bacteria are } \\
\text { excluded. } \\
\dagger \geq 5 \text { surface epithelium neutrophils per } \times 400 \text { field absent of menstrual endometrium } \\
\text { and/or } \geq 2 \text { stromal plasma cells per } \times 120 \text { field. } \\
\neq \text { Adjusted for age, race and self-reported partner treatment. }\end{array}$} \\
\hline
\end{tabular}

Long-term sequelae rates in the cohort were high among women testing positive for fastidious BV-associated bacteria (table 3). Endometrial detection of all four fastidious BV-associated bacteria was associated with recurrent PID. Similarly, detection of all BV-associated bacteria was significantly predictive of recurrent PID in subsets of women who tested negative for chlamydia and gonorrhoea (see online supplementary table S3, RR adj $4.7,95 \%$ CI 1.7 to 12.8 ). Detection of all four fastidious BV-associated bacteria in the cervix and/or endometrium was also associated with subsequent infertility, although risks were attenuated when these microbes were identified only in the endometrium. Similarly, women testing positive for all BV-associated bacteria were significantly more likely to develop infertility in subsets of women without gonorrhoea or chlamydia (see online supplementary table $\mathrm{S} 3, \mathrm{RR}_{\text {adj }} 3.4,95 \%$ CI 1.1 to 10.4$)$. In contrast to these novel bacteria, women with chlamydial infection had a marginal elevation in infertility risk $\left(\mathrm{RR}_{\mathrm{adj}} 1.9,95 \%\right.$ CI 0.9 to 4.2$)$ and those with gonococcal infection had no increased infertility risk $\left(\mathrm{RR}_{\mathrm{adj}} 1.1,95 \% \mathrm{CI} 0.6\right.$ to 2.2). Neither U. urealyticum nor U. parvum were consistently associated with long-term morbidity.

\section{DISCUSSION}

In our study of 545 women with clinically suspected PID, women who tested positive for $S$. sanguinegens, S. amnionii, A. vaginae or BVAB1 were more likely to have endometritis at PID diagnosis and experience recurrent PID and subsequent infertility. Women who tested positive for all four BV-associated bacteria in the endometrium had a twofold increased likelihood of having histologically confirmed endometritis, were nearly six times as likely to experience persistent endometritis after PID treatment and were four times as likely to have recurrent PID. 
Table 3 Long-term sequelae following pelvic inflammatory disease (PID) with selected fastidious bacterial vaginosis-associated bacteria $(\mathrm{BVAB})^{*}$ and ureaplasmal bacteria

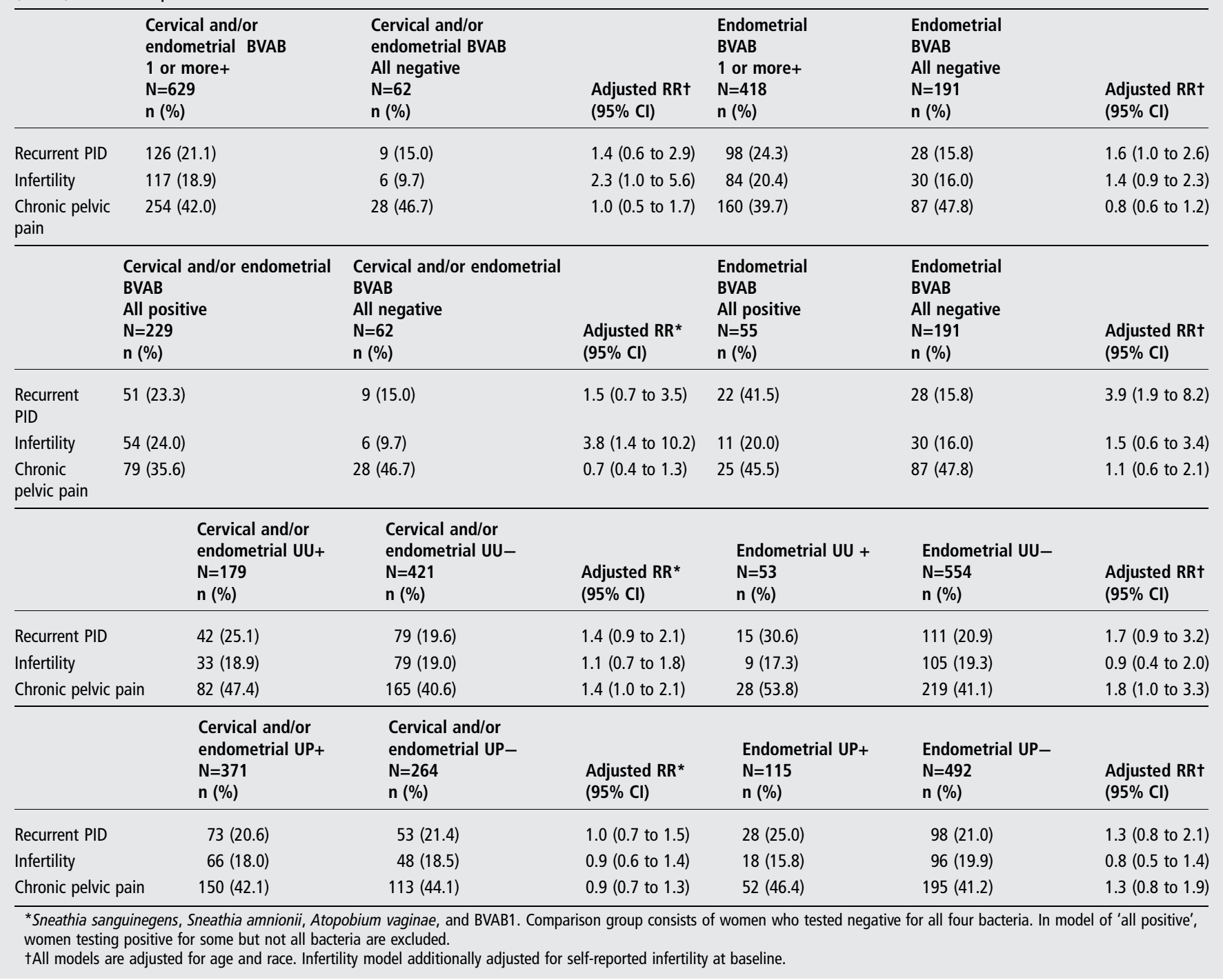

Further, women who tested positive for all four BVAB in the cervix and/or endometrium were nearly four times as likely to experience subsequent infertility.

To our knowledge, this is the first cohort study to show that molecularly identified BV-associated bacteria are associated with PID and its sequelae. Results are consistent with our prior culture study demonstrating that anaerobic black-pigmented Gram-negative rods are associated with endometritis, independent of chlamydia and gonorrhoea. ${ }^{6}$ Additionally, we previously showed that a cluster of cultured vaginal BV-associated organisms (absence of hydrogen peroxide-producing lactobacillus, presence of $G$. vaginalis, Mycoplasma hominis, anaerobic Gram-negative rods and undifferentiated ureaplasmas) was associated with a twofold risk of incident PID. ${ }^{30}$ Mirroring results among men with urethritis, ${ }^{20} U$. parvum was not associated with any outcomes in this study, while the relationship between U. urealyticum and endometritis was modest.

Half or more of women testing positive for these select bacteria had persistent infection 30 days post-cefoxitin/doxycycline treatment. Women who tested positive for all four BV-associated bacteria in the endometrium were nearly four times as likely to experience short-term treatment failure. Moreover, women testing positive for fastidious BV-associated bacteria at baseline were nearly four times more likely than those without these pathogens to develop recurrent PID.

Whether Sneathia spp. and BVAB1 are sensitive to antibiotics is unclear due to the difficulty in culturing these bacteria, yet the high rates of persistent infection post-treatment in our study suggest that cefoxitin and doxycycline constitute suboptimal treatment. A. vaginae has been reported to be susceptible to cefoxitin. $^{12}$ Although it was often identified 30 days posttreatment in our study, it was not associated with persistent endometritis. The high rates of $U$. urealyticum and U. parvum persistence were predictable, as ureaplasmas have been shown to express tetracycline resistancew ${ }^{1}$ and contain tet $\mathrm{M}$ genes that encode such resistance. ${ }^{\mathrm{w} 2}$

Women testing positive for fastidious BV-associated bacteria at PID diagnosis were nearly four times as likely to develop subsequent infertility, even after adjustment for confounders. Our results extend previous culture studies demonstrating that BV categorised by Gram stain is associated with tubal factor infertility among women undergoing in vitro fertilisation. ${ }^{\text {w3 }}$ 
Major strengths of our study are the prospective design and the characterisation of specific BV-associated microorganisms. As our study is limited to four selected BV-associated bacteria measured using targeted qualitative PCR, further research examining concentrations of a broader phylogenetic range of BV-associated microbes among PID and infertility patients using high-throughput sequencing and quantitative real-time PCR assays is warranted. Further, it is possible that transcervical sampling of the endometrium may have resulted in contamination of endometrial biopsy specimens by vaginal or cervical microorganisms. However, as possible contamination would not be expected to differ by the study outcomes, it is unlikely to be a major source of bias. Further, associations between cervical PCR and outcomes should be unaffected. Lastly, our study is limited by the lack of a truly unaffected control group of women. All women enrolled in the PEACH study had clinically suspected PID. Thus, our comparison groups of women with negative PCR comprised women who presented with characteristics consistent with PID. This may have biased our findings towards the null.

Our results must be confirmed in other prospective studies as they highlight the concerning possibility that currently recommended antibiotics do not treat a range of BV-associated organisms associated with PID sequelae. Our findings highlight the need for commercially available and affordable multiplex PCR-based genital tract microorganism tests ${ }^{\mathrm{w} 4}$ of $\mathrm{BV}$-associated bacteria for incorporation in screening and treatment programmes to prevent PID. Such tests could also be included in standard work-up of PID to determine microbiological aetiology and allow clinicians to tailor patient treatment. For example, as our study found that $A$. vaginae persisted post-cefoxitin therapy, other CDC-recommended PID antibiotics active against $A$. vaginae ${ }^{\mathrm{w} 5}$ such as clindamycin or ampicillin/sulbactam might be used. Recent evidence suggests that the broad spectrum antibiotic nifuratel is effective against C. trachomatis and Mycoplasma spp. ${ }^{\mathrm{w} 6}$ as well as G. vaginalis and $A$. vaginae, without affecting lactobacilli. ${ }^{\mathrm{w} 7}$ However, no clinical trials of nifuratel for PID treatment have been conducted to date. The CDC treatment guidelines ${ }^{\mathrm{w} 8}$ suggest optional metronidazole inclusion for additional anaerobic coverage. However, as A. vaginae and Sneathia spp. have been shown to be metronidazole resistant in some studies, ${ }^{12}$ w5 clinical trials including metronidazole with other antimicrobials for mitigating short-term and long-term PID sequelae are needed.

We previously reported that C. trachomatis and N. gonorrhoea $e^{6}$ are associated with endometritis in this cohort. We now demonstrate that fastidious $\mathrm{BV}$-associated bacteria and chlamydia/gonorrhoea in combination elevates endometritis likelihood three-and-a-half-fold. As BV-associated bacteria and chlamydia/gonorrhoea were frequently co-present, and as the relationship between $\mathrm{BV}$-associated bacteria and endometritis was identified primarily among women with chlamydia and/or gonococcal infection, this suggests that chlamydia/gonorrhoea may pave the way for anaerobic bacteria ascension into the upper genital tract where they can persist post-PID treatment and cause recurrent PID and infertility, as demonstrated in our study. Alternatively or in addition, it is possible that persistent anaerobic infection may increase the risk of recurrent chlamydial or gonococcal infection.

That infertility was only marginally associated with chlamydial PID and not associated with gonococcal PID suggests that, in contrast to older studies that strongly implicated these bacteria in infertility, women in our study received timely and effective antibiotics for these pathogens. Indeed, approximately $90 \%$ of our patients were free of gonorrhoea/chlamydia at the 30-day follow-up. Moreover, the combination of gonorrhoea/chlamydia plus fastidious BV-associated bacteria produced no additional degree of persistent endometritis and long-term PID sequelae beyond the effect from BV-associated bacteria alone.

Currently, the approach for PID treatment is empiric, using broad spectrum antibiotics to target a range of pathogens but largely directed towards eliminating N. gonorrhoeae and/or C. trachomatis. However, approximately $60 \%$ of women on our cohort had non-gonococcal, non-chlamydial PID. ${ }^{4}$ Fastidious BV-associated bacteria, commonly found in the endometrium at baseline, often persisted after CDC-recommended PID treatment as did endometritis. A sizeable proportion of women receiving timely, standard PID treatment may thus have ongoing upper genital tract inflammation as a result of continued infection with previously unrecognised pathogens. Such treatment failure appears to eventuate recurrent PID and infertility among some women. Replication of our results would dictate that optimal diagnosis and treatment regimens for PID be re-evaluated.

\section{Key messages}

- Current pelvic inflammatory disease (PID) treatment regimens use broad spectrum antibiotics to target a range of pathogens, but largely directed towards eliminating Neisseria gonorrhoeae and/or Chlamydia trachomatis.

- Among women treated with cefoxitin and doxycycline, Sneathia sanguinegens/amnionii, bacterial vaginosis-associated bacteria 1 and Atopobium vaginae were associated with persistent endometritis, recurrent PID and infertility.

- Optimal antibiotic regimens for PID may require coverage for novel bacterial vaginosis-associated microbes.

\section{Handling editor Jackie A Cassell}

Contributors CLH was involved in the conception and design of the study, analysis and interpretation of data and wrote the paper. PAT was involved in the conception and design of the study, DNA extraction, PCR, analysis and interpretation of data and provided significant revisions. GT was involved in the conception and design of the study, analysis and interpretation of data, and provided significant revisions. SGA and JN were involved in the analysis and interpretation of data and samples and provided significant revisions. MJF was involved in the conception and design of the study, PCR, analysis and interpretation of data, and provided significant revisions. DCB was involved with acquisition of data, analysis of data and provided significant revisions. DHM was involved with the conception and design of the study, interpretation of data and provided significant revisions. BDT was involved in interpretation of data, drafting part of the background and provided significant revisions. RBN was involved in the conception and design of this study and the parent PEACH study, interpretation of data and provided significant revisions. All authors provided final approval.

Funding This work was supported by the Agency for Healthcare Research and Quality Development [HS08358-05 to RBN] and from the National Institute of Allergy and Infectious Diseases at the National Institutes of Health [5R01Al073940 to $\mathrm{CLH}$.

Competing interests None declared.

Patient consent No.

Provenance and peer review Not commissioned; externally peer reviewed.

Ethics approval University of Pittsburgh Institutional Review Board (IRB number: 0608052). 
Data sharing statement All data are stored at the University of Pittsburgh, Pittsburgh, PA, under the direction of Dr Catherine Haggerty (haggerty@pitt.edu). An outside individual wishing to access the data must collaborate with Dr Haggerty to do so. A written protocol must be submitted, reviewed and approved prior to initiation of any new projects. In order to ensure integrity of the data, all analyses are conducted at the University of Pittsburgh under the direction of Dr Catherine Haggerty.

Open Access This is an Open Access article distributed in accordance with the Creative Commons Attribution Non Commercial (CC BY-NC 4.0) license, which permits others to distribute, remix, adapt, build upon this work non-commercially, and license their derivative works on different terms, provided the original work is properly cited and the use is non-commercial. See: http://creativecommons.org/ licenses/by-nc/4.0/

\section{REFERENCES}

1 Westrom $L$, Joesoef $R$, Reynolds $G$, et al. Pelvic inflammatory disease and fertility. Sex Transm Dis 1992;19:185-92.

2 Wiesenfeld HC, Cates W Jr. Sexually transmitted diseases and infertility. In: Holmes KK, Sparling PF, Stamm WE, et al, eds. Sexually transmitted diseases. New York: McGraw-Hill, 2008:1511-27.

3 Barmat LI, Rauch E, Spandorfer $S$, et al. The effect of hydrosalpinges on IVF-ET outcome. J Assist Reprod Genet 1999;16:350-4.

4 Ness RB, Soper DE, Holley RL, et al. Effectiveness of inpatient and outpatient treatment strategies for women with pelvic Inflammatory Disease: results from the PID Evaluation and Clinical Health (PEACH) randomized trial. Am J Obstet Gynecol 2002;186:929-37.

5 Kiviat NB, Wolner-Hanssen P, Eschenbach DA, et al. Endometrial histopathology in patients with culture-proven upper genital tract infection and laparoscopically diagnosed acute salpingitis. Am J Surg Pathol 1990;14:167-75.

6 Haggerty $\mathrm{CL}$, Hillier SL, Bass DC, et al. Bacterial vaginosis and anaerobic bacteria are associated with endometritis. Clin Infect Dis 2004;39:990-5.

7 Hillier SL, Kiviat NB, Hawes SE, et al. Role of bacterial vaginosis-associated microorganisms in endometritis. Am J Obstet Gynecol 1996;175:435-41.

8 Fredricks DN, Fiedler TL, Marrazzo JM, et al. Molecular identification of bacteria associated with bacterial vaginosis. N Engl J Med 2005;353:1899-911.

9 Hanff PA, Rosol-Donoghue JA, Spiegel CA, et al. Leptotrichia sanguinegens sp. nov., a new agent of postpartum and neonatal bacteremia. Clin Infect Dis 1995;20 (Suppl 2):S237-9.

10 Gundi VA, Desbriere R, La Scola B. Leptotrichia amnionii and the female reproductive tract. Emerging Infect Dis 2004;10:2056-7.

11 Gardella C, Riley DE, Hitti J, et al. Identification and sequencing of bacterial rDNAs in culture-negative amniotic fluid from women in premature labor. Am J Perinatol 2004;21:319-23.

12 Geissdorfer W, Bohmer C, Pelz K, et al. Tuboovarian abscess caused by Atopobium vaginae following transvaginal oocyte recovery. J Clin Microbiol 2003;41:2788-90.

13 Yamagishi Y, Mikamo H, Tanaka K, et al. A case of uterine endometritis caused by Atopobium vaginae. J Infect Chemother 2011;17:119-21.
14 Knoester M, Lashley LE, Wessels $\mathrm{E}$, et al. First report of Atopobium vaginae bacteremia with fetal loss after chorionic villus sampling. J Clin Microbiol 2011;49:1684-6.

15 Hebb JK, Cohen CR, Astete SG, et al. Detection of novel organisms associated with salpingitis, by use of $16 \mathrm{~S}$ rDNA polymerase chain reaction. J Infect Dis 2004;190:2109-20.

16 Haggerty C, Totten P, Astete $S$, et al. Failure of cefoxitin and doxycycline to eradicate endometrial Mycoplasma genitalium and the consequence for clinical cure of pelvic inflammatory disease. Sex Transm Infect 2008;84: 338-42.

17 Cohen CR, Manhart LE, Bukusi EA, et al. Association between Mycoplasma genitalium and acute endometritis. Lancet 2002;359:765-6.

18 Henry-Suchet J, Catalan F, Loffredo V, et al. Microbiology of specimens obtained by laparoscopy from controls and from patients with pelvic inflammatory disease or infertility with tubal obstruction: Chlamydia trachomatis and Ureaplasma urealyticum. Am J Obstet Gynecol 1980;138:1022-5.

19 Robertson JA, Stemke GW, Davis JW Jr., et al. Proposal of Ureaplasma parvum sp. nov. and emended description of Ureaplasma urealyticum (Shepard et al. 1974) Robertson et al. 2001. Int J Syst Evol Microbiol 2002;52:587-97.

20 Bradshaw CS, Tabrizi SN, Fairley CK, et al. The association of Atopobium vaginae and Gardnerella vaginalis with bacterial vaginosis and recurrence after oral metronidazole therapy. J Infect Dis 2006;194:828-36.

21 Ness RB, Keder LM, Soper DE, et al. Oral contraception and the recognition of endometritis. Am J Obstet Gynecol 1997;176:580-5.

22 Manhart LE, Critchlow CW, Holmes KK, et al. Mucopurulent cervicitis and Mycoplasma genitalium. J Infect Dis 2003;187:650-7.

23 Haggerty $C$, Totten $P$, Ferris $M$, et al. Clinical characteristics of bacterial vaginosis among women testing positive for fastidious bacteria. Sex Transm Infect 2009;85:242-8

24 Zozaya-Hinchliffe M, Martin DH, Ferris MJ, et al. Prevalence and abundance of uncultivated Megasphaera-like bacteria in the human vaginal environment. App/ Environ Microbiol 2008;74:1656-9.

25 Xiao L, Glass Jl, Paralanov V, et al. Detection and characterization of human Ureaplasma species and serovars by real-time PCR. J Clin Microbiol 2010;48:2715-23.

26 Dutro SM, Hebb JK, Garin CA, et al. Development and performance of a microwell-plate-based polymerase chain reaction assay for Mycoplasma genitalium. Sex Transm Dis 2003;30:756-63.

27 Nugent RP, Krohn MA, Hillier SL. Reliability of diagnosing bacterial vaginosis is improved by a standardized Gram stain interpretation. J Clin Microbiol 1991;29:297-301.

28 Amsel R, Totten PA, Spiegel CA, et al. Nonspecific vaginitis. Diagnostic criteria and microbial and epidemiologic associations. Am J Med 1983;74:14-22.

29 Fredricks D, Fiedler T, Marrazzo J. Molecular identification of bacterial associated with bacterial vaginosis. N Engl J Med 2005;353:1899-911.

30 Ness RB, Kip KE, Hillier SL, et al. A cluster analysis of bacterial vaginosisassociated microflora and pelvic inflammatory disease. Am J Epidemiol 2005;162:585-90. 